International Journal of Engineering \& Technology, $7(2.15)(2018) 123-126$
International Journal of Engineering \& Technology
SPC
Website: www.sciencepubco.com/index.php/IJET
Research Paper

\title{
The moderating effect of environmental regulation and policy on the relationship between continuous process improvement and organizational performance: An empirical analysis
}

\author{
Mohamad Ghozali Hassan, Muslim Diekola Akanmu*, Ahmad Yusni Bahaudin \\ School of Technology Management and Logistics, Universiti Utara Malaysia, 06010 Sintok, Kedah, Malaysia \\ *Corresponding author E-mail: adiekola@gmail.com
}

\begin{abstract}
There have been inconsistencies in the implementation of TQM practices in the Malaysian Food and Beverage Companies and this has led to low sales and less competitive advantage in the industry. This study therefore aimed to investigate the moderating effects of environmental regulation and policy on the relationship between continuous process improvement and organizational performance. A Partial Least Square Structural Equation Modeling (PLS-SEM) was used to estimate the relationship among the above variables in the context of Malaysian Food and Beverage Companies. The results of this study revealed that continuous process improvement has always been a significant predictor of organizational performance by following the regulations and policy related to environment. The results confirmed that environmental regulation and policy moderates the relationship between continuous process improvement and organizational performance. The integration of strategies and practices will help organizations to enhance their performance through implementation of the suggested constructs in this study. The study also supported the premises of the contingency theory and the institutional theory by reaffirming the importance of the supportive environmental regulation and policy for any successful strategic implementation
\end{abstract}

Keywords: Continuous process improvement; Environmental regulation and policy; Food and beverage companies; Organizational performance; Total quality management.

\section{Introduction}

Malaysia is known as one of the well informed countries on policies of agriculture due to inextricable connection between critical research and technological dash that is financially supported by different sectors with enough budgetary allocation [1]. According to research conducted on marketing practices in Malaysian Agro-based industry [2], it is posited that agro-based products have shorter life span due to the nature of the products and they require good marketing practices to increase the sales. According to the report from Federation of Malaysian Manufacturers in joint collaboration with Malaysia External Trade Development Corporation directory on food and beverage industry group profile, the food processing sector accounts for $10 \%$ of Malaysia's manufacturing output. It boasts an export value of over RM5 billion (USD1.3 billion) billion) annually, representing $2 / 3^{\text {rd }}$ of the total food export of more than RM10 billion with processed food exported to 80 countries. In relation to any business, TQM is a managerial concept and tool with the objective to involve managers, employees and customers to yield continuous performance improvement [3]. Also, it is known by various names like continuous improvement, total quality and process improvement [4]. The association between innovation and TQM practice is conceptualized and hypothesized in a model to show that implementation of TQM strategic systems support innovation process in organization as a result of elements such as continuous process improvement [5]. With global comparison, Malaysia's sales of agricultural products are relatively low which can be attributed to low responsiveness of entrepreneurs in producing quality and competitive agro-based products [1]. One of the environmentally rich countries in the world is Malaysia with abundant mineral resources and high biodiversity, but presently the country faces some particular environmentally-related problems such as water pollution, air pollution and exploitation of natural resources [6]. Thus, in Malaysia, boosting indigenous technological capacity remains a major development challenge. In addition, continuous improvement in science and technology advancement contributes to the increase in toxicity and volume of waste generated due to the advent of industrialization and urbanization [7].

\section{Literature review}

\subsection{Continuous process improvement}

One of the commonly discussed TQM elements in literatures is continuous improvement or continuous process improvement [8]. Continuous process improvement has proven to be a powerful tool in organizations [9], particularly in enhancing performance. Innovation, competitiveness and performance are the aims of the current business environment under the condition that quality and continuous improvement becomes a prime mover in achieving these objectives. The study focuses on incorporating quality management and six-sigma for the continuous process improvement and development of higher education institutions. The finding shows that continuous process improvement is sustained by measuring the process quality, research outcomes and educational products and services [10]. In addition, it is argued that for continuous improvement to be efficiently manifested, teamwork has to be maintained [11]. 
According to the three renowned quality scholars [12-14], continuous process improvement is always a point of encouragement that necessitates competitiveness globally, distinguished by rapid change of technological advancement and customer demand for higher ground of value.

Summarily, continuous process improvement is conceptualized in terms of systematic improvement approach for organizational process, continuous look for ways to improve the manufacturing process, effective feedback system, standardized documentation of quality assurance, continuous review of organizational performance related issues, continuous evaluation of quality-related strategies and complete integration of the quality assurance system [9].

\subsection{Environmental regulation and policy (ERP)}

Environmental quality is measured by the level in which ERP is being properly followed. It is an attribute of the regulatory socio-natural relationship, the functional significance of which depends on the ability to reflect the maximum processes of environmental safety [15]. The high demand for compelling environmental regulation and policy on production processes and product end-of-life is promoted by concerns of customers for environmental protection [16]. The use of planning agreements to support sustainability and environmental preservation through a contextual framework that will draw collaborative planning theory and practice for agreement of plans together can be implemented as a tool to conserve and preserve environmental principles and values generally [17].

In Malaysia, the Environmental Quality Act 1974 referred to environment as the visible factors of the environs of the human beings that consist of land, water, atmosphere, climate, sound as well as biological and social factors of aesthetics. Environment is regarded as all things that surround a matter and having a direct impact on it. The environment in which man is encapsulated is affected by factors which may be natural, artificial, social and biological or psychological [18]. A natural environment is one in which human impact is kept under a certain limited level for human survival. In connection to this, economic activities are dependent on a specific type of climate, weather and natural resources. In addition, the natural environment is referred to as everything that is present on the surface of the earth like the land, water, plants and animals and is considered as what can be affected by human activity; for instance, the industrial development that is causing widespread pollution to our immediate environment [19].

\subsection{Organizational performance (OP)}

The increase in challenges of numerous organizations in achieving and sustaining competitive advantage through finance, operations and customer satisfaction has contributed to the gain of utmost attention to survive in a highly competitive environment of organizational performance. Due to this, organizational performance is simply regarded to be an outcome of a firm's activities over a given period of time [20]. Organizational performance is the corollary summation of productive assets made up of physical, human and capital resources purposely to fulfill a shared aim and objective, dream or vision [21]. In this study, OP is operationalized as a term that is made of three areas. Firstly, the financial performance that is made up of ROA, ROI and profits, second one is product market performance comprising market share; sales and lastly the return of shareholders comprising economic value added (EVA) as well as total shareholder return (TSR). The study revealed that external business environment has an impact on organizational performance.

Therefore, the main objective of the study is to empirically investigate the environmental regulation and policy impact on the relationship between TQM and organizational performance. This major objective is divided into two objectives, which are as follows:
- To investigate the impact of continuous improvement process on organizational performance

- To examine environmental regulation and policy's moderating effect on the relationship between continuous process improvement and organizational performance

\subsection{Hypothesis formulation}

Hypotheses to be tested in the research study are formulated and presented below:

$\mathrm{H}_{1}$ : Quality of process significantly affects performance of an organization.

$\mathrm{H}_{2}$ : Continuous process and service development significantly affect performance of an organization.

$\mathrm{H}_{3}$ : Feedback significantly affects performance of an organization. $\mathrm{H}_{4}$ : Environmental regulation and policy significantly moderates the effect of continuous process improvement on the organizational performance.

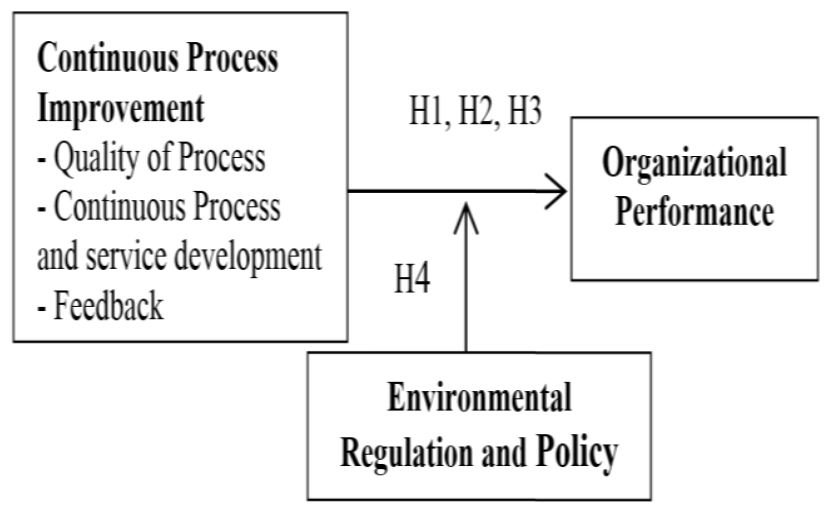

Fig.1: Conceptual research model

\section{Methodology}

This research work employed primary data which provides organizational performance records and accounts in a workable format. Questionnaires were provided to the top managers. The data was analyzed using SEM PLS. This study used a survey research as it follows a quantitative approach of study. In this context, questionnaire is suitably appropriate as a data gathering instrument. All the variables to be investigated in this study are continuous variables. They are continuous improvement process measured by quality of process, continuous process and service development and feedback, with organizational performance as the dependent variable and the environmental regulation and policy as the moderating variable [22]. Questionnaires were distributed to 250 Malaysian food and beverages companies. About 71 questionnaires were retrieved from the total questionnaires distributed.

\section{Results and discussion}

\subsection{The discriminant validity analysis}

The discriminant validity of the outer model for this study was confirmed by noting that the diagonal elements in the table are higher compared to the other elements of the column and row where they are located. From the testing made for construct validity of the outer model, the obtained results related to the hypothesis tests are confirmed to be reliable and valid.

\subsubsection{The assessment of the hypotheses testing procedure and inner model}

Following the confirmation of goodness of the outer model, the hypothesized relationships among the variables were tested next. The hypothesized model was tested by running algorithm using smart PLS. Table below shows the inner structural model results. 
Table 1: The discriminant validity matrix (latent variable correlation)

\begin{tabular}{c|c|c|c|c|c}
\hline & CP1 & CP2 & CP3 & DV & MV \\
\hline CPI1 & 0.944298 & & & \\
CPI2 & 0.871225 & 0.886948 & & & \\
CPI3 & 0.742913 & 0.918043 & 0.958693 & & \\
DV & 0.819781 & 0.851274 & 0.82657 & 0.803841 & \\
MV & 0.443233 & 0.585481 & 0.627307 & 0.603632 & 0.880277 \\
\hline
\end{tabular}

For the purpose of drawing conclusion on whether statistically, the path coefficients are significant or not, bootstrapping techniques were employed in this study with Smart PLS 2.0. As reported in Table 2, the t-values with path coefficient respectively were determined by employing bootstrapping technique and subsequently, $\mathrm{P}-\mathrm{Values}$ subsequently were generated. The results showed the following about continuous process improvement, CPI; CPI1 has significant effect on quality process $(\beta=0.272, \mathrm{t}=2.180, \mathrm{p}<$ $0.01), \mathrm{CPI} 2$ has no significant effect on continuous product and service development $(\beta=-0.021, \mathrm{t}=0.115, \mathrm{p}>0.1)$ while CPI3 positively and significantly affected feedback $(\beta=0.296, \mathrm{t}=$ $2.248, \mathrm{p}<0.01$ ), making the hypotheses $\mathrm{H}_{1}, \mathrm{H}_{2}$ and $\mathrm{H}_{3}$ supported, not supported and supported respectively. Lastly, the result $(\beta=$ $0.202, \mathrm{t}=1.689, \mathrm{p}<0.01)$ showed that ERP positively and significantly affected organizational performance and thus hypotheses $\mathrm{H}_{4}$ was supported.

\subsubsection{Testing the moderating effect of environmental regula- tions and policy}

For testing the moderating effect of ERP, Smart PLS 2.0 was used. As illustrated in Table 3, the results showed that there is a full moderating effect of ERP on the relationship between $\mathrm{CPI}$ and organizational performance that is significant at $(\beta=$ $0.743, \mathrm{t}=0.757, \mathrm{p}<0.01$ ). Therefore, hypotheses $\mathrm{H}_{4}$ was supported in this study. Table 4 summarizes the results of the tested hypothesis.

Table 2: Inner structural model results

\begin{tabular}{c|c|c|c|c|c}
\hline Hypothesis & Path Coefficient & Standard Error & T Statistics & P Value & Decision \\
\hline $\mathrm{H}_{1}:$ CPI1 -> DV & 0.272 & 0.125 & 2.180 & 0.002 & Supported \\
$\mathrm{H}_{2}:$ CPI2 -> DV & -0.021 & 0.202 & 0.115 & 0.450 & Not Supported \\
$\mathrm{H}_{3}:$ CPI3 -> DV & 0.296 & 0.139 & 2.248 & 0.001 & Supported \\
$\mathrm{H}_{4}:$ MV -> DV & -0.202 & 0.113 & 1.689 & 0.005 & Supported \\
\hline
\end{tabular}

Table 3: Testing the moderating effect of environmental regulation and policy

\begin{tabular}{c|c|c|c|c|c}
\hline Hypothesis & Path Coefficient & Standard Error & T Statistics & P Value & Bootstrapping Effect \\
\hline CPI1 -> DV & 0.743 & 0.981 & 0.757 & 0.450 & \\
CPI1 * MV -> DV & -0.705 & 1.341 & 0.525 & 0.300 & Moderating effect \\
CPI2 -> DV & 0.524 & 1.833 & 0.285 & 0.390 & \\
CPI2 * MV -> DV & -0.700 & 2.551 & 0.274 & 0.390 & Moderating effect \\
CPI3 -> DV & -1.150 & 1.222 & 0.941 & 0.170 & \\
CPI3 * MV -> DV & 1.994 & 1.624 & 1.227 & 0.110 & Moderating effect \\
MV -> DV & 0.374 & 0.374 & 1.001 & 0.160 & \\
\hline
\end{tabular}

Table 4: Summary of the results

\begin{tabular}{cllc}
\hline Hypothesis & \multicolumn{1}{c}{ Hypothesis Path } & Decision \\
\hline $\mathrm{H}_{1}$ & Quality of process has significant effect on organizational performance & Supported \\
$\mathrm{H}_{2}$ & Continuous Process and service Development has significant Effect on organizational performance & Not supported \\
$\mathrm{H}_{3}$ & Feedback has significant effect on organizational performance & Supported & Supported \\
$\mathrm{H}_{4}$ & Environmental regulation and policy moderates the effect of continuous process improvement & \\
\hline
\end{tabular}

\subsection{Discussion}

\subsubsection{Continuous process improvement and organization per- formance}

CPI is one of the key factors comprising the search for neverending improvement of the output performance [23]. According to the results, CPI is found to be significant with organizational performance in all dimensions. That is Continuous Process Improvement, CPI obtained the following results; CPI1 has significant effect on quality process $(\beta=0.272, \mathrm{t}=2.180, \mathrm{p}<$ $0.01)$, CPI 2 has no significant effect on continuous product and service development $(\beta=-0.021, \mathrm{t}=0.115, \mathrm{p}>0.1)$ while CPI3 positively and significantly affected feedback $(\beta=0.296, \mathrm{t}=$ 2.248, $\mathrm{p}<0.01$ ), making the hypotheses $\mathrm{H}_{1}, \mathrm{H}_{2}$ and $\mathrm{H}_{3}$ : supported, not supported and supported respectively. This result is in contrast to a previous study [24], but consistent with another study [25] that found continuous process improvement to significantly affect organizational performance.

The result shows that CPI practices are not given due attention and effective implementation in Malaysian Food and Beverage Companies (FBC). FBC as a sub-set of an agro-based industry focuses more on achieving the daily jobs related to issues happening within the unit of organizations and how it affects the employees and customers rather than to how service can be improved through implementation of CPI. All management practices should be covered by CPI. Specifically, the best practices to improve the CPI to cover all management practices are training, involvement, process quality, company products and services, feedback system.

\subsubsection{The moderating role of environmental regulation and} policy between CPI and organizational performance

As it can be seen in Table 4, environmental regulation and policy moderates TQM and organizational performance at the 0.01 level of significance $(\beta=0.374, \mathrm{t}=1.001, \mathrm{p}<0.01)$ according to the bootstrapping method. This result supported the hypotheses $\mathrm{H}_{4}$ of the study. Moreover, this finding confirmed the logical use of environmental regulation and policy as a practice that can help organizations to improve performance through TQM's continuous process improvement [26]. In other words, ERP in this study plays a role of the mechanism that explains the impact of TQM on the performance of organizations. Prior studies also evidenced the positive relationship between the two variables from one view and ERP from another view.

\subsection{Contribution}

This study provides some insights to public, manufacturing and service organizations in Malaysian and ASEAN region. For example, other industries in Malaysia or other Asian countries can take this study as a guideline when striving for excellence. In other words, FBC whether in Malaysia or outside can have many practical benefits as evidenced by the findings of this study. The extensive literature and arguments and the results should be taken into 
consideration from other industries to enhance performance. In this study, the most important factors discussed were CPI and ERP as necessary for any organization that wants to achieve success and competitive advantages. In some companies, TQM practice has been implemented without having information system to link the whole departments, while in other companies, they have systems but lacking in strategies and practices such as CPI. Therefore, the integration of these strategies and practices will help food and beverage companies to enhance their performance through implementation of the suggested constructs in this study concurrently. In addition, other private sectors can also leverage values from the findings of this study.

\section{Conclusion}

This study primarily examined the moderating role of environmental regulation and policy as a mechanism on the relationship between CPI and organizational performance. The results confirmed that ERP can enhance the role of CPI to achieve higher organizational performance. In pursuant of excellence, following the rules and regulations related to environment plays an important role in enhancing the organizational performance through implementing the policies on innovative strategies and practices. In summary, the results of this empirical study highlight new insights about how CPI and ERP can improve the organizational performance of food and beverage companies in the context of Malaysia.

\section{References}

[1] Adebowale AS (2013), Food production, hunger and poverty of public policy in Nigeria: A political economic analysis. International Journal of Research in Social Sciences 2, 20-25.

[2] Ahmad A (2009), Marketing practices among Malaysian SME's in agro-based industry. Prosiding Persidangan Kebangsaan Ekonomi Malaysia IV, 145-150.

[3] Akanmu MD, Bahaudin AY \& Jamaludin R (2017), A partial least square structural equation modelling preliminary analysis on total quality management elements and environmental regulation and policy influencing organisational performance in the food and beverage companies of Malaysia. International Journal of Productivity and Quality Management 22, 60-81.

[4] Allen RS \& Kilmann RH (2001), Aligning reward practices in support of total quality management. Business Horizons 44, 77-84.

[5] Bon AT \& Mustafa EM (2013), Impact of total quality management on innovation in service organizations: Literature review and new conceptual framework. Procedia Engineering 53, 516-529.

[6] Mohammad N (2011), Environmental law and policy practices in Malaysia: An empirical study. Australian Journal of Basic and Applied Sciences 5, 1248-1260.

[7] Sangodoyin AY \& Ipadeola SF (2000), Hazardous wastes assessing the efficacy of structures and approaches to management in Nigeria. Environmental Management and Health 11, 39-46.

[8] Intra C \& Zahn T (2014), Transformation-waves-A brick for a powerful and holistic continuous improvement process of a Lean production system. Procedia CIRP 17, 582-587.

[9] Krittanathip V, Rakkran S, Cha-um S \& Klamdej I (2013), Development of weighting on self-assessment evaluation for total quality management: A case study of wholesale sectors. Procedia-Social and Behavioral Sciences 88, 49-60.

[10] Suárez-Barraza MF, Ramis-Pujol J \& Tort-Martorell Llabrés X (2009), Continuous process improvement in Spanish local government: Conclusions and recommendations. International Journal of Quality and Service Sciences 1, 96-112.

[11] Atkinson C (1994), Continuous improvement: The ingredients of change. International Journal of Contemporary Hospitality Management 6, 6-8.

[12] Crosby PB (1979), Quality is free: The art of making quality certain, McGraw-Hill.

[13] Deming WE (1986), Out of the crisis, Cambridge University Press.

[14] Juran JM (1988), Juran's quality control handbook, McGraw-Hill.

[15] Chervinski A (2014), Ecological evaluation of economic evaluation of environmental quality. Procedia Economics and Finance 8, 150156.
[16] Santos-Reyes DE \& Lawlor-Wright T (2001), A design for the environment methodology to support an environmental management system. Integrated Manufacturing Systems 12, 323-332.

[17] Leshinsky R (2012), Use of planning agreements to support sustainability and environmental preservation: A case study from Victoria, Australia. International Journal of Law in the Built Environment 4, 157-172.

[18] Birnie PW \& Boyle AE (1994), International law and the environment, Oxford University Press.

[19] Hill MK (2010), Understanding environmental pollution, Cambridge University Press.

[20] Osundina KC \& Osundina JA (2012), Budgeting processes and the performance of food and beverages manufacturing companies in Nigeria. International Journal of Economic Development Research and Investment 3, 61-69.

[21] Adeoye AO \& Elegunde AF (2012), Impacts of external business environment on organisational performance in the food and beverage industry in Nigeria. British Journal of Arts and Social Sciences 6, 194-201.

[22] Zikmund WG, Babin BJ, Carr JC \& Griffin M (2013), Business research methods, Cengage Learning.

[23] Talib F, Rahman Z \& Qureshi MN (2013), An empirical investigation of relationship between total quality management practices and quality performance in Indian service companies. International Journal of Quality and Reliability Management 30, 280-318.

[24] Fotopoulos CV \& Psomas EL (2010), The structural relationships between TQM factors and organizational performance. TQM Journal 22, 539-552.

[25] Burli SB, Kotturshettar BB \& Dalmia RV (2012), Multiple performance measures: Six TQM practices. SCMS Journal of Indian Management 9, 69-79.

[26] Kaur M, Singh K \& Singh Ahuja I (2012), An evaluation of the synergic implementation of TQM and TPM paradigms on business performance. International Journal of Productivity and Performance Management 62, 66-84. 